\title{
A memória cultural mukongo em face de colonialidade: decolonialidade com a desobediência epistêmica ${ }^{1}$
}

\author{
La memoria cultural mukongo frente a la colonialidad: descolonialidad \\ con desobediencia epistémica
}

\author{
Mukongo cultural memory in the face of coloniality: decoloniality with \\ epistemic disobedience
}

Gabriel Ambrósio ${ }^{2}$

\begin{abstract}
Resumo
O presente trabalho visa abordar a minha memória cultural mukongo em face de colonialidade imposta pela assimilação cultural presente na sociedade do Zaire onde nasci. Tendo nascido fora da cultura latino-americana, dialogarei partindo do biolocal marcado por dois lócus enunciativos (Bessa-Oliveira, 2018, Nolasco $(2013,2018)$. Quero abordar alguns conceitos como nganga, muntu dentro da língua afrikana kikongo, como também a invisibilidade dos rituais religiosos ancestrais contemporaneamente. Objetivo é de narrar e reviver reapropriando-me como nativo, repensar e naturalizar a cultura, escrevendo na perspectiva teórica do eu sujeito muntu, e dos imaginários de lócus e da memória ancestral no corpo e arte Achinté (2009). Será que tenho o imaginário ligado à cultura ritual ancestral? Penso que essa invisibilidade é o resultado da colonialidade, essa colonialidade nos faz esquecer ancestralidade na cultura mukongo. Assim penso na imigração na América latina Brasil, em 2011, conheci um terreiro numa periferia. Lá e agora nascendo à pesquisa refletindo o meu projeto, baseado em Frantz Fanon (2008) em Pele Negra, Máscaras Brancas que inspirou-me a refletir sobre a cultura do colonizador de um lado, e de outro lado, a minha cultura local. Sinto-me exilado da minha espiritualidade e parto da força inspiradora em Ramón Grosfoguel (2009), Nolasco (2019), Hugo Achugar (2006),e Achinté (2009). Pensar e transgredir a epistemologia dentro da minha cultura local e naturalizar os conceitos como o eu sujeito pesquisador. Nos procedimentos metodológicos inspirando-me em estudos descoloniais fronteiriços dos latinoamericanos Nolasco $(2013,2019)$, para estabelecer a re-existência da cultura ancestral dentro do meu biolocalespiritual na memória simbólica e pela desobediência epistêmica da subalternidade imposta e recusar a colonialidade de modo transdisciplinar para emigrar na perspectiva decolonial. Usar a reflexão metodológica a minha própria experiência nas leituras teóricas da pós-graduação, permite-me fazer essa viagem entre o lócus daqui, para refletir lá, sobretudo, o meu imaginário dos espaços simbólicos silenciados Mignolo $(2008,2003)$ na decolonialidade e desobediência epistêmica caminho para então pensar e repensar o lugar da cultura Kanda comunidade no sentido local.
\end{abstract}

Palavras-chave: Memória cultural mukongo; colonialidade; desobediência epistêmica; decolonialidade.

\section{Resumen}

El presente trabajo tiene como objetivo acercarme a mi memoria cultural mukongo frente a la colonialidad impuesta por la asimilación cultural presente en la sociedad de Zaire donde nací. Habiendo nacido de la cultura latinoamericana, dialogaré a partir de lo biolocal marcado por dos locus enunciativos (Bessa-Oliveira, 2018, Nolasco $(2013,2018)$. Quiero abordar algunos conceptos como nganga, muntu dentro del idioma afrikaans Kikongo, así como la invisibilidad. de rituales religiosos ancestrales al mismo tiempo. El objetivo es narrar y revivir, reapropiando como nativa, repensando y naturalizando la cultura, escribiendo en la perspectiva teórica del yo sujeto muntu, y del imaginario del locus y la memoria ancestral en el cuerpo y el arte Achinté (2009)

\footnotetext{
${ }^{1}$ Artigo apresentado no Latinidades- Fórum Latino-Americano de Estudos Fronteiriços, na modalidade online, 2020.

${ }^{2}$ Mestrando em Estudos de Linguagens na Universidade Federal do Mato do Sul. Campo Grande, MS. Brasil.

Bolsista CAPES. E-mail ambrosionuni@gmail.com
} 
¿Tengo el imaginario conectado a la cultura ritual ancestral? Creo que la invisibilidad es el resultado de la colonialidad, esta colonialidad nos hace olvidar la ascendencia en la cultura Mukongo. Entonces pienso en la inmigración en América Latina Brasil, en 2011, conocí a un terreiro en una periferia Ahí y ahora naciendo para investigar reflejando mi proyecto, basado en Frantz Fanon (2008) en Black Skin, White Masks que me inspiró a reflexionar en la cultura del colonizador por un lado, y por el otro, mi cultura local. Me siento exiliado de mi espiritualidad y comienzo de la fuerza inspiradora en Ramón Grosfoguel (2009), Nolasco (2019), Hugo Achugar (2006) y Achinté (2009). Pensar y transgredir la epistemología dentro de mi cultura local y naturalizar conceptos como sujeto de autoinvestigación. En los procedimientos metodológicos inspirados en los estudios de frontera descolonial de los latinoamericanos Nolasco (2013, 2019), establecer la reexistencia de la cultura ancestral dentro de mi memoria biolocal-espiritual en la memoria simbólica y por la desobediencia epistémica de la subordinación impuesta y rechazar la colonialidad. de manera transdisciplinar para emigrar en la perspectiva decolonial. Utilizando la reflexión metodológica, mi propia experiencia en las lecturas teóricas de los estudios de posgrado, me permite hacer este recorrido entre el locus aquí, para reflexionar allí, sobre todo, mi imaginario de los espacios simbólicos silenciados Mignolo $(2008,2003)$ en la descolonialidad y la desobediencia. forma epistémica de pensar y repensar el lugar de la cultura Kanda - comunidad en el sentido local.

Keywords: Memoria cultural mukongo; colonialidad; desobediencia epistémica; decolonialidad.

\begin{abstract}
The present work aims to approach my mukongo cultural memory in the face of coloniality imposed by the cultural assimilation present in the society of Zaire where I was born. Having been born out of Latin American culture, I will dialogue starting from the biolocal marked by two enunciative locus (Bessa-Oliveira, 2018, Nolasco $(2013,2018)$. I want to address some concepts like nganga, muntu within the Afrikaans Kikongo language, as well as invisibility of ancestral religious rituals at the same time. The objective is to narrate and relive, reappropriating myself as a native, rethinking and naturalizing culture, writing in the theoretical perspective of the muntu subject self, and of the imagery of locus and ancestral memory in the body and art Achinté (2009) Do I have the imagery connected to ancestral ritual culture? I think that invisibility is the result of coloniality, this coloniality makes us forget ancestry in Mukongo culture. So I think of immigration in Latin America Brazil, in 2011, I met a terreiro in a periphery There and now being born to research reflecting my project, based on Frantz Fanon (2008) in Black Skin, White Masks that inspired me to reflect on the culture of the colonizer on the one hand, and on the other, my local culture. I feel exiled from my spirituality and I start from the inspiring force in Ramón Grosfoguel (2009), Nolasco (2019), Hugo Achugar (2006), and Achinté (2009). Thinking and transgressing epistemology within my local culture and naturalizing concepts as the selfresearching subject. In the methodological procedures inspired by decolonial border studies by Latin Americans Nolasco $(2013,2019)$, to establish the re-existence of ancestral culture within my biolocal-spiritual in symbolic memory and by the epistemic disobedience of the imposed subordination and to reject coloniality in a transdisciplinary way to emigrate in the decolonial perspective. Using methodological reflection, my own experience in the theoretical readings of graduate studies, allows me to make this journey between the locus here, to reflect there, above all, my imagery of the symbolic spaces silenced Mignolo (2008, 2003) in decoloniality and disobedience epistemic way to think and rethink the place of Kanda culture - community in the local sense.
\end{abstract}

Keywords: Mukongo cultural memory; coloniality; epistemic disobedience; decoloniality.

\title{
1. Introdução
}

"A civilização branca, a cultura europeia, impuseram ao negro um desvio existencial" (Fanon, 2008, p. 30).

A minha experiência e reflexões, partem do ensaio de Frantz Fanon (2008) em Pele negra, máscara Branca e através dele, reflito a imposição cultural da civilização colonial. Penso também no romance Pepetela A Geração da Utopia (2004) que aparece o termo 
kalunga, por exemplo, mas tenho outro imaginário ancestral do kalunga na minha comunidade remetendo algo ligado à divindade. Kalunga é local cheio de pedras, água e mata. Mas o que parece na obra de Pepetela diz "Kalunga- nome do Deus supremo" (PEPETELA, 2004, p.356). O meu imaginário do lócus chamado Kalunga tem outro sentido ancestral das tradições quer dos cristãos quer do escritor angolano. Eu, enquanto leitor e pesquisador, trago aqui esse olhar diferente de kalunga como um local da minha comunidade de origem.

No entanto, usarei outros conceitos como substantivos próprios, verbos na língua materna para esses relatos da memória do biolócus. Há também outros conceitos da língua kikongo como nganga e muntu que nas traduções não trazem vibração nativa culturalmente. E mesmo a espiritualidade ancestral está na ordem da colonialidade, pois a vinculação religiosa, não passa de colonização e assimilação dentro do corpo, da arte, do local da minha origem. Hoje existem religiões cristãs que desprezam rituais locais, por exemplo, desde a invasão colonial em que aprenderam os saberes linguísticos locais e usaram a língua kikongo para doutrinar a comunidade na visão teológica imperial. Esse é resultado da assimilação que Fanon (2008), afirma que a civilização europeia ofuscou a realidade cultural na minha região lá e como aqui na América Latina as religiões de matriz africana, que sofrem por espaço e desprezo, devido ao sistema moderno que está presente nos países colonizados, subalternizados e marcados pela cultura ocidental.

A memória do imaginário ancestral está sendo naturalizado, pois na narrativa local, encontro certa confusão entre o que os padres católicos instalados no interior do bairro onde foi enterrado o meu umbigo. O umbigo para minha comunidade, é um vínculo forte cultural e espiritual da existência e agora também da minha re(e)xistência. Eu nasci e cresci em Nenzinga-Tomboko- Nzadi/Zaire, Angola- Áfrika ${ }^{3}$. Este é uma verdadeira prática desobediente e decolonialidade escrever África com K. Sinto e vejo que, o povo desconhece algumas memórias como o de Kalunga. Tendo um aporte teórico Walter Mignolo (2003) em Histórias Locais/ projetos globais, e "Desobediência epistêmica" (2008), Edgar Nolasco (2018) em "Descolonizando a pesquisa acadêmica" 2019), Bessa-Oliveira (2018) em Paisagens biográficas pós-coloniais, Anibal Quijano (2002) A colonialidade de poder, Ramon Grosfoguel (2009) no texto "Para descolonizar os estudos de economia política e estudos pós-coloniais” e Bunseki Fu-kiau, Tiganá Santos (2019) em “A cosmologia africana dos bantu-kongo por Fu-kiu" entre outros nessa narrativa biolocal.

\footnotetext{
${ }^{3}$ A escrita do substantivo (África)- Áfrika estando na língua afrikana kikongo e usarei neste texto e o seu adjetivo masculino afrikano também. Como forma de desobediência e reexistência linguística do sujeito pesquisador.
} 
O crítico literário Hugo Achugar (2006) em Planetas sem boca trata entre muitas reflexões ligadas a América Latina, mas principalmente "a periferia" ou então "o lugar a partir de onde falo" (ACHUGAR, 2006, p. 14). A minha condição aqui no Brasil, aprendi e reaprendi a cultura afro-brasileira, a nativa que tem sido menosprezada pela colonialidade bem como a memória que carrego da cultura mukongo, também desprezado por isso. Considero importante o meu imaginário consciente do lócus, o de lá e daqui, no entanto, cresci ouvindo que, os meus avós, não sabiam escrever, mas falavam língua kikongo. Porque narro isso? Porque os padres é que passaram a falar dos autóctones pela escrita e isso continuou até aos nossos dias, mas para significar conforme Alban Adolfo Achinté (2009) em Artísticas indígenas y afrocolombianos: entre has memórias afirma a importância da memória oral, ou seja, "finalmente, se la historia, la memória las tradiciones orales son fundamentales en los procesos de reafirmación identitaria " (ACHINTÉ, 2009,p. 94). Desde minha chegada ao Brasil, tenho contato com os afrodescendentes e me revelam, contam a importância da oralidade nos nossos povos, mas em minha história local existe, embora ultimamente, não tem sido valorizado pela juventude, que não escutam os mais velhos, pois o ensino formal tem outras referências é o que senti quando em 2018 estava lá na comunidade. Mas para a opção decolonial inspirada pelos latinos americanos, o próprio Fanon, estou revivendo a memória oral para desobedecer a colonialidade, subalternidade presente na cultura mukongo.

Existem muitas histórias de viés colonial ocidental, que contaram histórias locais sem estar na memória local, e inclusive o pensar de muitos que escreveram/ escrevem a história desse povo que estão no lócus chamado Nzadi- (Zaire), Zaire é aportuguesação/ aportuguesamento do substantivo próprio na lógica colonial da História do povo Kongo. Kongo - Mukongo é o singular do bakongo que denomina o povo ou grupo sociocultural situado sob a margem do rio Nzadi na região sul do equador, noroeste de Angola. Mas os mais velhos (akuluntu), por exemplo, Makuta $\operatorname{Nkondo}^{4}(2019)$, num dos artigos sobre a origem do nome Bakongo. Akuluntu na língua materna são referências culturais nos Mukongos, pois são fontes de saberes, experiências locais como considera Mignolo (2003) em Histórias locais/ projetos globais. No entanto, faz parte do continente afrikano e o país é Angola.

\footnotetext{
${ }^{4}$ Makuta Nkondo "a origem do nome bakongo" in < http://wizi-kongo.com/historia-do-reino-do-kongo/origemdo-nome-bakongo/> acesso em 10 de maio de 2020.
} 
Angola fica situado na região ocidental afrikano, conforme o portal oficial ${ }^{5} . \mathrm{Nzadi}^{* 6} \mathrm{e}$ divata dietu- divata diame ${ }^{* 7}$ em vez de usar o termo colonial (município do Tomboko- uso o conceito anterior que Nenzinga), assim fica Nenzinga divata diame- Nenzinga é minha terra. Essa é resultado da memória da língua local.

\section{Quem é o mukongo e sua cultura em função da colonialidade?}

Mukongo é o sujeito que nasceu dentro do grupo sociocultural no noroeste de Angola, na verdade, pode-se afirmar como singular do bakongo. Sendo o sujeito que está narrando é um mukongo, tendo a língua materna o kikongo. Não havia um livro sagrado, mas sagrada era a palavra e a oralidade conforme ouvia na comunidade. Já a função da colonialidade por meio das trocas coloniais começou-se a escrever na língua kikongo e traduzindo-se os conceitos de forma inadequada.

No entanto, o conceito de nganga traduzido como viés religioso colonial como feiticeiro-curandeiro, mas na língua local não têm essa semântica, logo penso em Mignolo (2003) na obra Histórias locais / projetos globais que evoca reflexão de como os outros criaram as situações culturais e linguísticas como uma das armas poderosas para a construção de comunidade impostas de lógica diferente saberes (MIGNOLO, 2003). Nganga são os sábios locais, tem o domínio natural no conhecimento de plantas medicinais, a espiritualidade ancestral, pois são minhas referências, desobedecendo à epistemologia colonial. Como afirma Fu-kiau e SANTOS (2019), não se compreendem com a lógica da imposição semântica da colonialidade: "Nganga não é somente uma pessoa de teoria, conforme as ciências sociais ocidentais. Nganga cria, inventa, executa sua especialidade" (SANTOS, 2019, p. 178). A cultura educacional e linguística não cabe traduzir os códigos ancestrais com olhar eurocêntrico. Essa força impositiva que recuso para ressignificar o que tem sido negado, silenciado.

Contudo, com a colonialidade foram silenciadas desde o século XIV que se teve contato com os brancos, até então ancestralidade era respeitada por todos bakongos no lócus Nenzinga- Mbanza- Kongo, ora Nzadi. O desvio de alienação e assimilação à cultura europeia na comunidade e criando outra lógica cultural alheia aos modos ancestrais conforme no

\footnotetext{
${ }^{5}$ Localização geográfica de Angola < http://m.portalangop.co.ao/angola/pt_pt/portal/informacoes/angola/sobreangola/2013/8/36/Pais,63104f71-04ae-4ab4-a28c-e301bde8afe0.html> Acesso em 10 de maio de 2020.

${ }^{6}$ É o termo que usarei durante esse texto, pois como proposta da desobediência epistêmica como Mignolo (2017).

${ }^{7}$ Divata dietu - divata diame corresponde à expressão divata dietu- nossa terra, e divata diame- minha terra.
} 
epigrafe revelando em (FANON, 2008). E noutra reflexão ele escreveu "Para o segundo, é como vítima de um regime baseado na exploração de uma raça por outra, no desprezo de uma parte da humanidade por uma civilização tida por superior" (FANON, 2008, p. 185).

A ideia trazida por colonizadores que explorou a cultura, a terra, a ilusória superioridade sobre o bantu $^{8}$ - como plural de muntu junto do singular, traduzindo na verdade, estaríamos a repetir o desprezo que a cultura europeia e sua epistemologia colonial. Muntu não é personalidade que carrega a máscara semanticamente, na ontologia local e ancestral, o muntu é mais que o físico, e sim elementos integrados energéticos, o mistério existencial e suas relações socioculturais (SANTOS, 2019). Muntu não traduzível no eurocentrismo. Na verdade, o kikongo foi negado e depois ressignificado por aqueles ensinaram os colonizadores para traduzir a bíblia na língua afrikana ${ }^{9}$ kikongo, com objetivo eram a divulgação e doutrinar os habitantes da região. Muitos conceitos têm a imposição da civilização branca européia. Mas hoje a periferia é a imposição da colonialidade conforme revela MIGNOLO (2017, 2008), a minha narrativa nesse contexto, está com essa experiência e reflexão sobre os princípios dos rituais ancestrais que se fazem neste lócus, brasileiro que conheci o candomblé em 2011. Os quilombos que resistem a colonialidade de poder conforme MIGNOLO (2003) e QUIJANO (2002), nos seus lócus na cultura marginalizada e afastado nas periferias.

Foi nessa colonialidade que quando escrevi que, muntu não se traduz, pois o conceito de muntu, não se enquadra na lógica violenta e imperial cultural Ocidental. O que eles negam é o direito de fruição da cultura local, a religiosidade ora a espiritualidade mukongo. Quando Fanon escreveu Pele negra, máscaras brancas há 68 anos, pensando a colonialidade dentro da cultura afrikana, foram marcantes e o hoje temos os desafios de todos.

Os dois têm de se afastar das vozes desumanas de seus ancestrais respectivos, a fim de que nasça uma autêntica comunicação. Antes de se engajar na voz positiva, há a ser realizada uma tentativa de desalienação em prol da liberdade (FANON, 2008, p. 191).

Contudo, os colonizados e seus ancestrais foram afastados de suas práticas e saberes. Os brancos que se apropriaram no direito de subjugar os subalternos que educaram sem descolonizar as práticas educacionais e religiosas. $\mathrm{Na}$ verdade, como opressores não podem fazer, eu penso que como transgressor e desobediente, estou com energia e esforço decolonial,

\footnotetext{
${ }^{8} \mathrm{O}$ termo bantu na perspectiva colonial traduz-se por plural de pessoas, mas na perspectiva descolonial não tem tradução bem como o seu singular Muntu. Na cultura do kanda e local, não se dá esse conceito à pessoa no sentido de que, um muntu é muito mais que pessoa. É a intraduzibilidade que falo.

${ }^{9}$ Os substantivos África e seu adjetivo estão sendo escrito na língua afrikana kikongo e desobedecendo a escrita colonial. Pois na minha língua não tem a letra $\mathrm{C}$, mas tem $\mathrm{K}$. Eis a razão neste texto será usada.
} 
para reconhecer a diferença colonial e reescrever com 'experivivências' no Centro Oeste, Brasil, como lócus.

A partir daqui, sinto o outro lócus para compartilhar o impacto da colonialidade que a juventude tem dificuldade de conceder valor a língua afrikana e local, ou seja, há jovens que não pensam nas línguas e nos conceitos fora da colonialidade de poder quase impossível, reviver e reaprender a espiritualidade ancestral e desalienar totalmente. Há também outro desafio para descolonizar as mentes do muntu mukongo. Somente assim e como "os desafios do presente e do futuro consistem em poder imaginar uma vez que nos liberamos da matriz colonial de poder e nos lançamos ao vazio da vida plena e harmônica" (MIGNOLO, 2017b, p. 31). Caminhar nestas reflexões envolve uma desobediência e descolonização do próprio pensamento incutido durante séculos.

O contato desastroso que a hospitalidade traída pelos invasores colonizadores, seguiuse a forçosa escravização e racialização, surge também "a matriz racial de poder é um mecanismo pelo qual não somente as pessoas, mas as línguas e as religiões conhecimentos e regiões do planeta são racializadas" (MIGNOLO, 2008.p. 293). As religiões de matriz afrikana sentem, os nativos da América e os pretos convivem com racismo e racialização. Sobre língua, reflito em Fanon quando escrevera "Este é um problema terrível em nossa vida. Falar é estar em condições de empregar uma certa sintaxe, possuir a morfologia de tal ou qual língua, mas é sobretudo assumir uma cultura, suportar o peso de uma civilização" (FANON, 2008, p. 33).

Exatamente essa assimilação, a colonialidade a que se usar a decolonialidade, desassimilação, reviver a reaprender a espiritualidade ancestral, porém a invasão moderna desde o século XV que Nzadi tem sido colocado "missão cristã” à civilização, na verdade, era uma forma

Sob sua retórica triunfante de salvação e boa vida para todos- a perpetuação da lógica da colonialidade, ou seja, da apropriação massiva da terra (e hoje dos recursos naturais), a massiva exploração do trabalho ( escravidão aberta do século XVI até o século XVIII, para escravidão disfarçada até ao século vinte e um) [...](MIGNOLO, 2008,p. 293).

Além da exploração da terra, exploração da força do trabalho e há também o silenciamento culpabilização simbólica da história local pela escravidão. $\mathrm{O}$ imaginário histórico e literário muitas vezes, vem justificando a escravidão e responsabilizando, culpando os reis do Kongo pela escravidão dos bakongos. Ou seja, a colonialidade reinando.

Infelizmente, nem todos os assassinatos massivos foram registrados com o mesmo valor e a mesma visibilidade. Os critérios não mencionados para o valor das vidas humanas são um óbvio sinal (de uma interpretação descolonial) de política 
escondida de identidade imperial: quer dizer, o valor de vidas humanas a qual pertence a vida do enunciador, se torna uma vara de medida para avaliar outras vidas humanas que não têm opção intelectual e poder institucional para contar a história e classificar os eventos de acordo com um classificação de vidas humanas:ou seja, de acordo com uma classificação racista (MIGNOLO, 2008,p. 294).

Não sentem nada pela história e colonialidade de poder, continua invisibilizar ou velar o valor das vidas nativas 'indígenas', dos quilombos, os pretos não se comovem, por exemplo, em comparação a história dos judeus no século XX. Há terreiros de candomblé sofrendo violência da intolerância religiosa de alguns grupos evangélicos, ora, alguns justificando a sua violência não só fisicamente, mas simbolicamente ou pela cultura

[...] línguas marginalizadas e denegridas, religiões e formas de pensar estão sendo reescritas em confronto com as categorias de pensamento do ocidente. Pensamento de fronteira ou epistemologia de fronteira é uma das consequências e a saída para evitar tanto o fundamento ocidental quanto o não ocidental (MIGNOLO, 2008, p. 297).

Nenhum país afrikano tem língua oficial não europeia, suas religiões que são apropriadas por afrikanos ou assimilarem inconscientemente assim como a reproduzirem a colonialidade. Pois a amnésia "dessa memória das civilizações e cosmologias indígenas", $\underline{o S}$ bakongos (MIGNOLO, 2008.p. 303). Grifo meu. Tal como os latinos e indígenas, eu mukongo/bakongo, temos uma cosmologia que quase é desconhecida por fato da assimilação da cultura europeia, ou desvio existencial das culturas locais.

$\mathrm{Na}$ cultura mukongo ancestral a cosmologia envolve três elementos interligados "ngolo, energia, no mundo físico, kunseke" (SANTOS, 2019, p. 32). Elementos que são as forças ancestrais para a cosmologia. Ngolo são energias de força existencial, kunseke é o mundo espiritual no meu sentir e viver. E na cosmogonia que narro a partir do Pepetela, o escritor nos diz "cosmogonia é importante, toda religião tem suas respostas, e essas perguntas sobre o espaço e o universo" (PEPETELA, 2004, p. 320). No caso aqui, a religião é parte da colonialidade e o escritor não está ausente no pensamento colonial, pois descolonizar o olhar ocidental nem sempre está presente no fazer arte dos colonizados. Os mukongos não tinham nenhuma religião formal, mas sim há práticas e rituais que são diferentes na concepção cristã.

\subsection{O Mukongo e reviver, reaprender a cultura de olhar decolonial e com a desobediência epistêmica}

A utopia da modernidade está atrapalhar as mentes da juventude, o silenciamento a espiritualidade ancestral, há toda necessidade no esforço em desobedecer e para enriquecerme na teoria do eu sujeito, o muntu para reviver a cultura sob perspectiva que está sendo 
narrada a partir da memória e reflexão de outros pesquisadores. "Descolonial significa pensar a partir da exterioridade e em uma posição epistêmica subalterna- vis-à -vil a hegemonia que cria, constrói, erege um exterior a fim de assegurar sua interioridade" (MIGNOLO, 2008, p. 304). A posição epistêmica para reaprender a cultura começa no uso da própria língua materna.

No entanto, a língua que é ndinga e nkadilu que significa o bem estar da vivência cultural ressignificado, não mais no sentido colonial, mas dentro da cultura do muntu dentro da comunidade e do biolócus não vista pela colonialidade parece termos alheios, porque é complicada a tradução conforme Boaventura Sousa Santos e Hissa Viana (2011) em "Transdisciplinaridade e ecologia de saberes" afirmaram que

Há diferentes saberes, mas diferentes universos simbólicos, diferentes concepções do mundo, que condicionam os diferentes os saberes. Aí, de fato, a tradução é mais complicada: uma tradução intercultural (SANTOS \& HISSA, 2011, p. 23).

Os problemas de tradução nos séculos passados não pensaram os diferentes saberes dos povos e suas cosmologias, suas línguas, apenas traduziu-se como subalternos no caso nganga - traduziram-se como feiticeiros e sem mais nada.

Ao passo que Mignolo, reflete e com razão em afirmar que "precisamos desatar o nó, aprender a desaprender, e aprender a reaprender a cada passo" ( Mignolo, 2008,p. 305). Quando eles tentaram traduzir o muntu aprendi e estou a reviver a cultura do muntu, estou reaprender a cultura local e que não traduzo. Tiganá Santana Neves Santos (2019) na tese do doutorado sobre cosmologia afrikana dos bantu- kongo quando temos o Kala segundo Fukiau não é correspondente à lógica colonial. "Kala é a vontade mais forte de existência do muntu” (FU- KIAU apud SANTOS, 2019, p.146). Assim Narro que Kanda- comunidade não é equivalente ao ocidente, ou seja, o Kala - bem estar é diferente na cultura europeia. Kala mu Kanda é reaprender como eu, sujeito muntu. Como Mignolo (2008) afirma que a cultura ocidental não pode ser igual ao "que foca no bem estar da comunidade em vez de acumulação privada e pessoal” (MIGNOLO, 2008.p. 307). Nós, ou eu mukongo no kala - princípio vivencial como era antes da colonialidade, hoje está modernizado e eu naturalizo o conceito.

Voltando ao Nenzinga que é um substantivo próprio, mas é tido como periférico dentro do país, Nzadi -Zaire, no geral está perdendo a educação familiar como princípio cultural ancestral, o modo comunitário da educação, a socialização e as linhas de familiaridade kanda- comunidade de famílias em kikongo Ndezi-Kindezi ${ }^{10}$ foi desviado pela

\footnotetext{
${ }^{10}$ Conceito mukongo para a arte de educar, cuidar as crianças- bana/ yana. Quando era um mwana era chamado de Ndezi.
} 
colonialidade de poder sua globalização conforme (QUIJANO, 2002). Através dessa violência simbólica destorceu o pensamento e a cultura local. Foi o que aconteceu quando começaram a proibir a poligamia dentro de kanda, pois os missionários, pastores comentaram sem nunca ter entendido a cultura poligâmica nos bakongos. A colonialidade roubou e pilhou a simbologia cultural, as tradições e não foge na linha, aliás, foi lá que recebeu os "civilizadores" europeus: hoje, está-se lamentando. A pergunta é, será que tenho o imaginário ritual ancestral? Para isso, é preciso reviver, reaprender a cultura local, sem pensar na civilização que fragmentou os princípios ancestrais, no Nenzinga, lá e no atual lócus onde está o bio do sujeito bem como sem obedecer epistemologicamente.

Imaginando alguns rituais religiosos, como agradecer o ntoto, nza (terra, a natureza) prática comunitária quase perdida, canções e brincadeiras da minha infância, não é vista ou esquecida pela assimilação, àqueles alienados a civilização ocidental. Narrar decolonialmente, eu sou do Nenzinga que está na memória. Tenho kalunga que na cultura afro-brasileira está representado nos rituais dos terreiros, levando o imaginário ancestral da minha memória (ACHINTÉ, 2009). Não quero que se pense em algo especial como

Pensar práticas culturais de maneira diferente, sem evidenciar características que reforçam o passado e não tornem o presente como inferior, é uma condição epistemológica para evidenciá-las sem torná-las melhor do que outras (BESSAOLIVEIRA, 2018, p.63).

Estou sentindo e repensando o quão a condição epistemológica que despreza os saberes fora da lógica ocidental.

Quando evoco o termo divata diame, refiro-me a terra / aldeia e também ao meu corpo. Nitu é o corpo- meu, com simbologia Kalunga sendo símbolo ancestral espiritual, na cosmologia local (Fu- Kiau, 2019). Pensando conforme o pesquisador e professor Nolasco (2019), em por uma gramática pedagógica da fronteira-sul: Exterioridade, há uma referência teórica e profunda que nos alimenta a memória pensando na opção advinda pela decolonialidade e sobre o campo político que tem um lugar de origem- Nenzinga - Nzadi ou divata diame/ a terra comunitária o nitu como corpo política.

Se o corpo-político reside do lado escuro da modernidade ou do pensamento moderno ocidental ou, como o prefiro do outro lado da fronteira, então somente aproximamo-nos mais devidamente dos corpos outros epistêmicos, se nos valermos da epistemologia fronteiriça do pensamento descolonial, do fazer descolonial que resulta na teorização é na opção descolonial por meio da qual se instaura a desobediência epistêmica que move a reflexão inicial de base descolonial (...) (NOLASCO, 2019, p. 28). 
Contextualizando o meu lugar, a minha cultura que foi desviada pelo sistema colonial que impera dentro do país e a capital do Nzadi- Mbanza- Kongo que é o centro político e administrativo da colonialidade. O outro lugar no centro- Oeste, Brasil, também é um loci dessa memória. Repensar essa lógica colonial por meio da desobediência e da experiência local, e das Histórias locais e os projetos globais MIGNOLO (2003). Faz a diferença no pesquisador. Não saímos da colonialidade que resulta na transmutação de formas contemporâneas ou modernas que na verdade é modernidade ou colonialidade de poder, pois são ligados, ou seja,

Não existe modernidade sem colonialidade, que a colonialidade do poder subjaz à construção da nação tanto nas histórias locais das nações que conceberam e implementaram projetos globais que lhes diziam respeito, mas sem sua participação direta (MIGNOLO, 2003, p. 74).

A partir da colonialidade que traz o capitalismo na cultura local, é preciso " dispensar. a cultura mukongo que tem sido afetado e se apropriando nos casamentos extorquindo as famílias dos homens, só assim poderemos reviver o modo comunitário do casamento baseado na compreensão conjunta sem mais o capitalismo na cultura.

$\mathrm{Na}$ perspectiva dialógica latino-americana em estudos fronteiriços e conceitual de origem cultural local pensar como periférico silenciado do lócus afrikano. Mas sinto o bio no lócus, ou seja, "Pesquisador a partir de onde se pensa faz toda diferença para o pesquisador que se sabe sente e pensa que a inserção de seu bios na origem de sua reflexão crítica faz toda a diferença”(NOLASCO, 2018,p. 13). Eis um diálogo perfeito da minha inspiração latinoamericana para pensar a origem do meu bio como pesquisador. Nesse sentido, pesquisar e narrar é também forma de desobedecer à epistêmica imposta, pois pensar a decolonialidade, reviver, reolhar a cultura na forma teórica começando pelo lócus, sobre crítica do eu sujeito pesquisador, conforme o pesquisador na reflexão

Tomando o bios do sujeito, pensando numa proposição teórico-crítica, e o lugar de onde emergem esse sujeito e suas práticas, é levar em consideração o personagem que envolve papel fundamental nas práticas socioculturais (BESSA- OLIVEIRA, 2018, p.67).

O meu lugar de nascimento, da memória da infância agora do eu sujeito pesquisador, a vivência que tenho e o que penso e crítico. Refletindo como sujeito e a experiência cotidiana além da universidade, mas como da vivência dos ecos da violência da colonialidade.

Essa colonialidade que afasta os terreiros na periferia, trazendo a reflexão do professor e crítico Grosfoguel (2009) em Descolonizar os estudos de economia política escrevendo que as religiões de matriz afrikana postas na periferia da colonialidade, ora "A pretensa 
superioridade do saber europeu nas mais diversas áreas da vida foi importante aspectos da colonialidade do poder no sistema mundo-colonial/moderno. Os saberes subalternos foram excluídos e ou ignorados" (GROSFOGUEL, 2009, p. 405). Além de silenciados, foram adulterados os seus verdadeiros sentidos semânticos das línguas. Na perspectiva dialógica latino-americana em estudos fronteiriços e conceituais que uso nesta narrativa para pensar a cultural local, mas também pensar como periférico silenciado do lócus afrikano e aqui no Brasil, como localização atual e nele resistindo. A perspectiva do "pertencimento ao lócus", ou seja,

Da noção de pertencimento ao lócus cultural como condição para estabelecimento de um discurso crítico específico. (...) os deslocamentos críticos na geografia global, mas também reconhecem que fora preciso fazê-lo, de certa forma, para reler seus loci de origem (BESSA-OLIVEIRA, 2018, p. 67).

Assim para o pesquisador é preciso capacidade para reler os lócus de origem apesar dos deslocamentos que estão dentro dos discursos marcados pelas memórias.

No entanto, as memórias, os discursos e lugares alguns são desviados pelo olhar civilizacional colonial estamos nos descolonizar não mais na forma cultural política imposta, mas da forma epistêmica "uma condição epistêmica enquanto consciência de sujeito colonizado para entender essa abordagem teórica do próprio sujeito da crítica" (BESSAOLIVEIRA, 2018, p. 66). A minha crítica como sujeito pensando o conceito "cidade" não é igual que no Brasil, por exemplo, para mim, divata é o local sujeito pesquisador. $O$ divata dietu equivale na língua colonial nossa cidade/ comunidade. Cidade é Kanda dietu/ nossa comunidade. Bem como os termos província, municípios, ou seja, todas essas denominações não terão significado na cultura mukongo, pois minha língua e o bio lócus epistêmicos decoloniais não terá o mesmo significado na modernidade. Essa cultura Mukongo- local, o lócus cultural que difere na visão crítica do próprio sujeito pesquisador e da colonialidade. Pois estamos Sikameme- despertados que

A pós-colonialidade está entranhada em cada história local e, mais que um significado vazio, é uma lógica a entre todas elas. É o conectivo, em outras palavras, que pode inserir a diversidade das historias locais num projeto universal, deslocando o universalismo abstrato de UMA história local, onde se criou e imaginou o sistema mundial colonial moderno [...] (MIGNOLO, 2003, apud BESSA-OLIVEIRA, 2018, p.72).

Para expor os conceitos que não estão na colonialidade, por exemplo, quando imagino e escrevo na língua materna kulendi kudizaya ko e nkadilu- significa não seja ignorante da sua cultura. Vale reforçar que os conceitos são ressignificados e inspirando-me "A decolonialidade requere desobediência epistêmica" (MIGNOLO, 2017 b, p.30). Neste sentido, 
é a revivência e resistência da memória cultural da língua e dos teóricos que estão influenciando-me a repensar o saber local. Conforme já referenciado no Mignolo e também o Fanon quando imagino a colonização como causa desse desvio existencial que pode resistir a partir da proposta "epistêmica" crítica do Eu sujeito pesquisador. Minha consciência deve estar aberta para pensar, ora sikama- desperto e Sikamesa- despertar para conhecimento localO nzaylu- conhecimento na língua afrikana kikongo. Tuzaya diaka - equivale o reconhecimento. Mas levar a língua na pesquisa é o ato de coragem igual ao que está entre parênteses ( nata ndinga kassi vo tuavanga zay). Ke landa yawu ko - não segue- logo há aqui uma "desobediência epistêmica com relação à epistemologia moderna" (NOLASCO, 2019, p.15). Pensar na minha língua kikongo, dentro da academia que ainda está na colonialidade de que excluem "línguas locais, as memórias subalternas às crenças e o princípio de saberes outros que escapa ao conhecimento moderno" (MIGNOLO, apud NOLASCO, 2019, p. 15). Além da exclusão, mas há certa inferiorização cultural e social que estou ressignificando os saberes locais.

Sentir diante do Kanda, comunidade não no sentido único semântico pela colonialidade, os bakongo dentro da cultura e dos lócus do bio-sujeito, pesquisador que sente e carrega consigo experiências do Brasil e de mukongo. A reapropriação cultural é na base da desobediência epistêmica proposta do Mignolo citado por Nolasco (2019) Reafirmar como os teóricos que "a desobediência epistêmica é opção descolonial por desvincular os conceitos ocidentais e de acumulação de conhecimentos" ( MIGNOLO apud NOLASCO, 2019, p. 22). Refletindo essa forma de conceber e pesquisar a cultura do sujeito.

Porque importante essa crítica dentro da memória? Respondo em breves linhas que todo sujeito educado pela colonialidade de poder após o despertar da consciência crítica tem o dever de repensar a história, a literatura e o modo de pesquisar a própria experiência que busca descolonizar-se a si, a comunidade e alma conforme a reflexão Nolasco, 2019, p. 23: "A necessidade de descolonizar as almas e as mentes dos dividuos presos à subjetividade de moderna, bem como, por exemplo, por extensão, a teoria, a crítica e o discurso moderno". E após de anos vivendo a colonialidade, porque não pensar na cultura e se comunicar com ela, trazendo na pesquisa acadêmica para repensar que "não há outra maneira de saber, fazer e ser descolonialmente, senão mediante um compromisso com a desobediência epistêmica" (MIGNOLO, 2017b, p.23). O compromisso não pode ser limitado ademais, a influência está garantindo descolonizar as próprias memórias a partir do Campo Grande, Mato Grosso do Sul. 


\section{Conclusões preliminares}

Esse relato de experiências de tomar o discurso de pertencimento da minha língua nativa apesar dos deslocamentos e vivências teóricas dos pensadores latino-americanos, mas pensar os conceitos nganga e muntu, kala, sikamesa, Zaya e tantos outros usados na narrativa do sujeito pesquisador e meu projeto em curso, pensando ou sentindo que A Geração da Utopia e ensaios do Fanon me ajudam fazer os estudos transdisciplinares, mas principalmente os críticos e teóricos que foram dando força na pesquisa, na desobediência epistêmica nas várias reflexões. Aprendendo e reaprendendo os rituais da resistência ancestral que sinto e revivo, com a desobediência epistêmica em curso.

Compartilhar essas vivências de sentir é pertinente e causam impacto como pesquisador que está na periferia e partindo dela reafirmo- como nativo que foi invadido pelo eurocentrismo. A ferida não está curada, o sujeito não está com única visão da subalternidade, mas para demonstrar o não silenciamento dentro dessa narrativa de memórias. As dificuldades de referências teóricas locais para ajudar a repensar, tem sido uma realidade. Portanto, essa pesquisa não está acabada, apenas começando. As reflexões que estão surgindo vão ser difundidas na comunidade de origem e também na minha convivência na universidade para explorar por meio da pesquisa e resistência desobediente são grandes desafios do futuro. Ressignificar os conceitos considerando a semântica e cultura local, será uma descolonização linguística nos próprios falantes e nos rituais locais.

\section{Referências}

ACHUGAR, Hugo. Planetas sem boca: escritos efêmeros sobre arte, cultura e literatura. Tradução Lyslei Nascimento. Belo Horizonte: Editora UFMG, 2006. (obra completa)

ACHINTÉ, Albán Adolfo. Artistas indígenas y afrocolombianos: entre las memorías y las cosmovisiones. In Arte y Estética en la encrucijada descolonial/ compilado por Zulma Palermo $-1^{\text {a }}$ Ed. Buenas Aires: Del Signo, 2009. (p.83-112). (capitulo do livro)

QUIJANO, Aníbal. Colonialidade, poder globalização e democracia. In Novos Rumos. Ano 17, No 37, 2002. Disponível em< https://revistas.marilia.unesp.br/index.php/novosrumos/article/view/2192 acesso em Outubro de 2020.

BESSA- Oliveira, Marcos Antônio. Paisagens Biográficas pós-coloniais: Retratos da Cultura local sul Mato-Grossense. Campo Grande, MS. Life Editora, 2018.(obra completa)

FANON, Frantz. Pele negra, máscaras brancas. Tradução de Renato da Silveira, Salvador. EDUFBA, 2008. (obra completa) 
GROSFOGUEL, Ramón. Para descolonizar os Estudos de economia política e Estudos póscoloniais: Transmodernidade, pensamento de Fronteira e colonialidade global. In Epistemologias do Sul. Orgs. Boaventura Sousa Santos e Maria Paula Meneses-(CES) editora Almedina, Coimbra, 2009. (capitulo de livro)

MIGNOLO. Walter. Desobediência epistêmica: a opção descolonial e o significado de identidade em política. Tradução Ângela Lopes Norte. Caderno de letras da UFF- dossiê: literatura, língua e identidade. 34. p. 287-322. 2008. (Artigo em periódico)

MIGNOLO. Walter. Desafios decoloniais hoje. In Epistemologia do Sul, Foz do Iguaçu/ PR, 1(1), PP.12-32, 2017. (artigo em periódico físico)

MIGNOLO. Walter. Histórias Locais/ Projetos Globais: Colonialidade, saberes Subalternos e Pensamento Liminar. Tradução de Solange Ribeiro de Oliveira. Belo Horizonte, Ed. UFMG, 2003. (obra completa)

MIGNOLO. Walter. Colonialidade: O lado mais escuro da Modernidade. Tradução de Marco Oliveira. In revista brasileira de ciências sociais. Vol. $32 \mathrm{~N}^{\circ}$ 94, 2017. (artigo em periódico digital) disponível em https://www.scielo.br/pdf/rbcsoc/v32n94/0102-6909-rbcsoc3294022017.pdf acesso em Junho 2020.

NOLASCO, Cézar Edgar. Descolonizando a pesquisando acadêmica: uma teorização sem disciplinas. In cadernos de estudos culturais, Campo Grande, Ms. v 1, p.9-21. jan./jun. 2018.( artigo em cadernos de estudos culturais).

NOLASCO, Cézar Edgar. Por uma Gramática pedagógica da Fronteira-Sul: Exterioridades. In caderno de estudos culturais, Campo Grande, Ms. v 1, p.9-29, jan./jun. 2019. ( artigo em cadernos de estudos culturais).

NOLASCO, Cézar Edgar. Perto de coração selbaje da crítica fronteriza. São Carlos: Pedro \&João editores, 2013. (obra completa)

PEPETELA. A Geração da Utopia. Editorial Nzila. Luanda, 2004. (Obra completa) SANTOS, Tiganá Santana Neves. A cosmologia africana dos bantu-kongo por Bunseki Fu kiau: Tradução negra, reflexões e diálogos a partir do Brasil. 2019. 233 f. Tese de doutorado- Faculdade de Letras e Ciências Humanas da Universidade de São Paulo, 2019. (Tese).

SANTOS, Boaventura Sousa de. HISSA, Viana. Transdisciplinaridade e ecologia de saberes. In conversações de arte e de ciência. Cassio E. Hissa Viana organizador. Belo Horizonte, Editora UFMG, 2011 (p. 17-34). (Capítulo do livro). 